\title{
SORPTION AND DIFFUSION OF WATER VAPOUR ON EDIBLE FILMS
}

\author{
D. Berkün", D. Balköse, F. Tihmınlıŏglu and S. A. Altınkaya \\ Izmir Institute of Technology, Department of Chemical Engineering, Gülbahçe Köyü, 35437 Urla-Izmir, Turkey
}

Two types of films consisting of sodium salt of carboxymethyl cellulose (NaCMC) and hydroxypropyl cellulose (HPC) as film forming materials and glycerin as plasticizer were prepared, characterized and their water vapour sorption properties were determined.

The water sorption isotherms of the films were measured using a magnetic suspension balance. Results show that diffusion of water vapour in $\mathrm{NaCMC}$ based film is faster than that in HPC based films, due to the heterogeneous structure and larger pore dimensions of the NaCMC films.

Keywords: cellulose films, diffusion, sorption, surface characterisation

\section{Introduction}

An edible coating or film has been defined as a thin, continuous layer of edible materials, which may be eaten together with the food, formed or placed, on or between foods or food components. Their function is to provide a barrier to mass transfer (water, gas and lipids), to serve as a carrier of food ingredients and additives (pigments, flavours, etc.), or to provide mechanical and microbial protection.

Water vapour adsorption data give the hydration properties of polymers. Thus, sorption isotherms (adsorption and desorption) of these films have been extensively studied [1-6] to investigate the moisture sorption behaviour of methyl cellulose films in order to evaluate some functional properties of films such as barrier property and stability of the films.

The objective of this work is to produce and characterize cellulose-based films. For this purpose sodium carboxymethyl cellulose (NaCMC) and hydroxypropyl cellulose (HPC) were used as the cellulose-based film forming materials. Films were characterized by using scanning electron microscopy (SEM), differential scanning calorimetry (DSC), X-ray diffraction analysis (XRD). In addition, the water vapour sorption properties of the films were determined.

\section{Experimental}

\section{Materials}

The film forming materials hydroxypropyl cellulose (HPC) $\left(M_{\mathrm{w}}=370.000 \mathrm{~g} \mathrm{~mol}^{-1}\right)$ and carboxymethyl cellulose sodium salt (NaCMC) $\left(M_{\mathrm{w}}=250.000 \mathrm{~g} \mathrm{~mol}^{-1}\right)$, used in this study, were supplied by Sigma-Aldrich. Glycerol was used as the plasticizer and was purchased from Merck. Deionized water was used as a solvent throughout the experiment.

\section{Film preparation}

To prepare films HPC or NaCMC (3, 4 or $5 \mathrm{~g}$ ) were first dissolved in deionised water $\left(100 \mathrm{~cm}^{3}\right)$ at room temperature by continuously stirring the solution for $4 \mathrm{~h}$. After complete dissolution of film forming materials, glycerol was added as a plasticizer at $10 \%$ dry mass and the solutions were homogenized with a magnetic stirrer at room temperature for $1 \mathrm{~h}$. Then, the solutions were kept in a vacuum oven at $25^{\circ} \mathrm{C}$ for about $48 \mathrm{~h}$ to remove air bubbles or dissolved air. Finally, the solutions were spread on glass plates by using an automatic film applicator (Sheen Automatic Film Applicator 1133N). The spread films were dried at room temperature for $48 \mathrm{~h}$, then at $60^{\circ} \mathrm{C}$ in an oven for $25 \mathrm{~min}$. Finally they were detached from the glass plates, covered with paper and stored at room temperature. The thickness of the films were measured with a digital micrometer at ten different locations. Film thicknesses were approximately measured as 10,20 and $30 \mu \mathrm{m}$ for films prepared from solutions with 3,4 , 5 mass $\%$ polymer concentration, respectively.

\section{Methods}

Morphology of the films using SEM

Each film was mounted on aluminum stubs using aluminum sticky tape and coated with gold palladium film in a VG Microtech SC 7610 Sputter coater. Then, the specimen was examined using a Philips XL 30S FEG electron microscope. 
X-Ray diffraction analysis (XRD)

NaCMC and HPC films were analyzed by using a Philips X'pert Pro. Diffractometer with $\mathrm{CuK}_{\alpha}$ radiation. The scattering angle (20) was varied from 5 to $70^{\circ}$.

\section{Differential scanning calorimetry (DSC)}

DSC analysis was used to determine the glass transition temperature $\left(T_{\mathrm{g}}\right)$ of the films. For this purpose, film samples (3.4-5.2 $\mathrm{mg}$ ) placed in alumina crucibles were heated from room temperature to over $600^{\circ} \mathrm{C}$ at a heating rate of $10^{\circ} \mathrm{C} \min ^{-1}$ under nitrogen purge (flow rate $=40 \mathrm{~cm}^{3} \mathrm{~min}^{-1}$ ) using a Shimadzu DSC-50 differential scanning calorimeter.

Measurements of sorption isotherms of films

The water vapour sorption isotherms were determined by gravimetric sorption experiments conducted in a magnetic suspension balance (Rubotherm). To obtain sorption isotherms of water vapour the mass was usually measured gravimetrically as a function of pressure varied stepwise [7]. During these experiments, film samples were placed into the measuring cell with multi-tray sample holder. The column enclosing the sample was heated up to $60^{\circ} \mathrm{C}$ using a water bath and vacuum was applied to the column by a rotary vane pump up to $0.01 \mathrm{~Pa}$ to remove the water desorbed from the samples during the heating process for $4 \mathrm{~h}$. Then, the column was kept at $30^{\circ} \mathrm{C}$ and the system was allowed to reach equilibrium in $24 \mathrm{~h}$. Water was heated in a flask by using a constant temperature bath and water vapour was sent to the column until equilibrium was reached. When equilibrium was obtained, valves of the column were closed and the vapour pressure of the water was increased by increasing the temperature of the water in the flask. Then, by opening the valves of the column, water vapour was sent to the column until a new equilibrium was reached. This procedure was continued until the temperature of the water vapour in the flask was $5^{\circ} \mathrm{C}$ below the column temperature.

\section{Result and discussions}

\section{Characterization of the edible films}

Morphology of the films

SEM was used to determine the structure of the $\mathrm{NaCMC}$ and HPC based edible films. It can be seen from Fig. 1 that both films have porous structures. However, HPC based edible films have a relatively more homogenous porous structure in comparison with NaCMC based edible films. The cross sectional micrographs of the film samples with magnification at

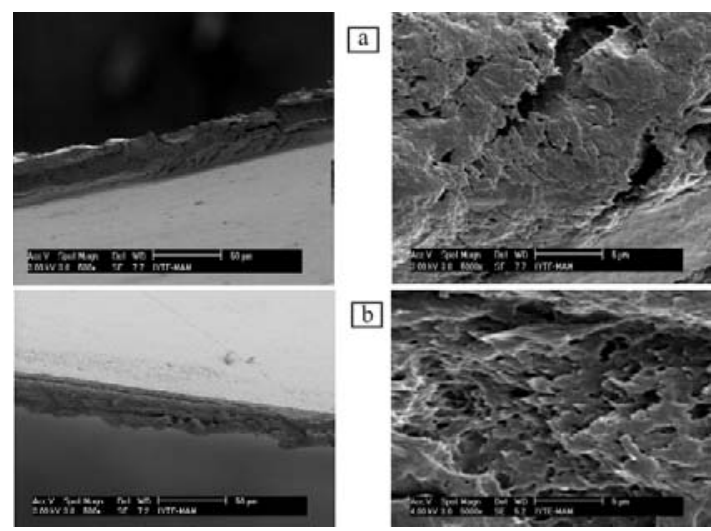

Fig. 1 SEM of the $a-N a C M C$ and $b-$ HPC based films, respectively obtained from $3 \%$ polymer solution $(\mathrm{N}=500 \mathrm{x}$ and $5000 \mathrm{x}$, respectively)
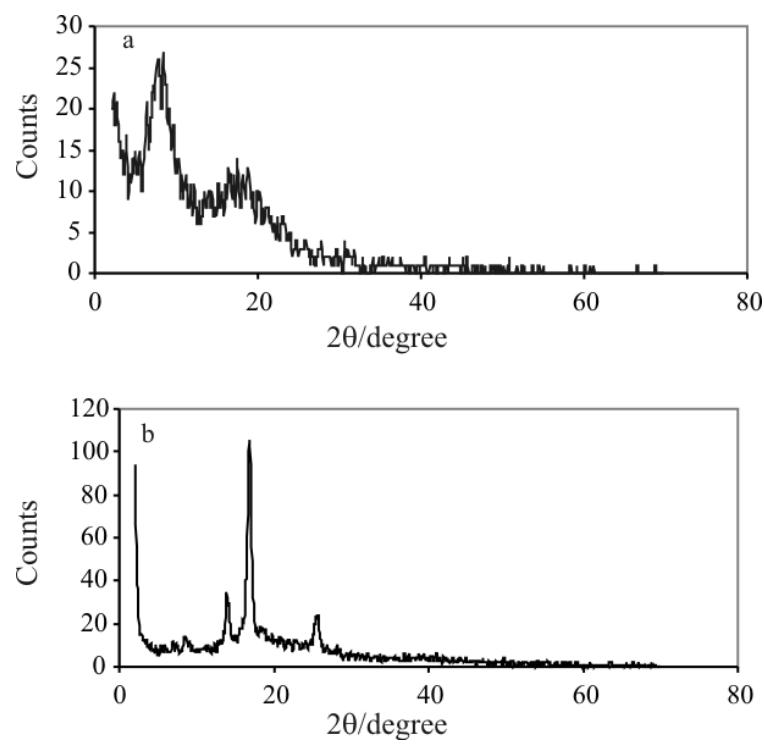

Fig. $2 \mathrm{X}$-ray diffraction diagrams of the a - HPC and $\mathrm{b}-\mathrm{NaCMC}$ based films

$5000 \times$ indicate that HPC films contain many small pores with dimensions of $\sim 0.5-1 \mu \mathrm{m}$.

\section{Crystallinity of the films}

XRD analyses were applied to investigate the crystallinity of the NaCMC and HPC based edible films. XRD diagram of HPC film (Fig. 2a) shows an amorphous structure. However XRD analysis of NaCMC film showed crystalline peaks at $2 \theta$ values of $14,16.9$ and $25.2^{\circ}$ (Fig. 2b).

\section{Differential scanning calorimetric (DSC) analysis}

Figure 3 a shows DSC curves for $\mathrm{NaCMC}$ based edible films prepared from three different concentrations. An endotherm having a maximum between $83-98^{\circ} \mathrm{C}$ was observed due to dehydration and evaporation of water from the films that are above their glass transition temperature. Indeed all films were prepared 
with 10 mass $\%$ glycerin to lower their $T_{\mathrm{g}}$ value below room temperature. The DSC analysis of all $\mathrm{NaCMC}$ edible films show one endotherm at $76^{\circ} \mathrm{C}$. On the other hand, the DSC curves of HPC films show a broad endotherm in the range of $70-85^{\circ} \mathrm{C}$, corresponding to the loss of residual water as illustrated in Fig. $3 \mathrm{~b}$.

DSC curves also indicated that NaCMC and HPC based films had $T_{\mathrm{g}}$ values that were lower than room temperature. Thus rubbery films were used in the sorption and desorption experiments.

\section{Sorption isotherms of edible films}

The relationship between water activity $\left(a_{\mathrm{w}}\right)$ and the moisture content of the films (at constant temperature) is shown in moisture sorption isotherms. Figure 4 shows
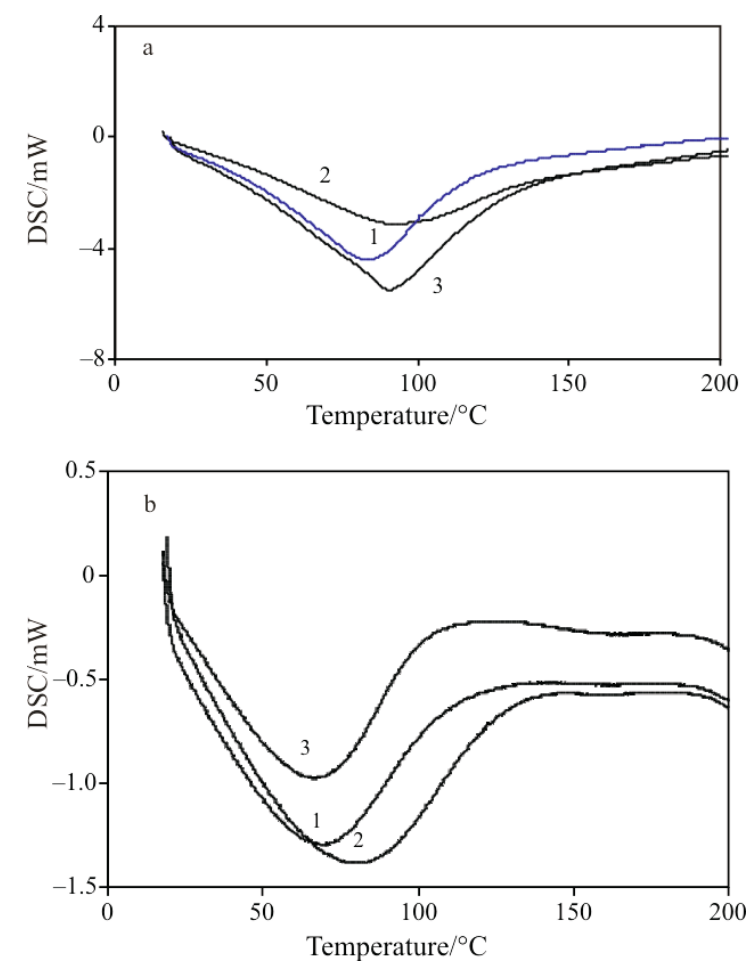

Fig. 3 DSC curves of $\mathrm{a}-\mathrm{NaCMC}$ and $\mathrm{b}-\mathrm{HPC}$ based edible film from: $1-3 \%, 2-4 \%, 3-5 \%$ polymer solution

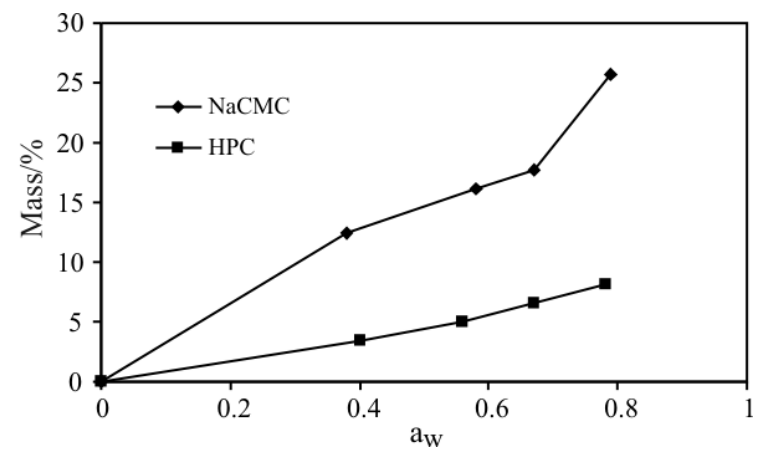

Fig. 4 Moisture sorption isotherms of $\mathrm{NaCMC}$ and $\mathrm{HPC}$ based films prepared from solution concentrations of $3 \%$ in microbalance the equilibrium water content of the $\mathrm{NaCMC}$ and $\mathrm{HPC}$ based edible films as a function of water activity at $25^{\circ} \mathrm{C}$ and the effect of polymer concentration on the moisture-sorption isotherms of the films. NaCMC based edible films have higher sorption capacity than HPC based edible films. As seen from Fig. 4 water vapour sorption capacity of the NaCMC and HPC based films was 70 and 25 mass $\%$, respectively at $90 \%$ relative humidity $(\mathrm{RH})$ As evident in Fig. 4 the sorption curves of HPC and $\mathrm{NaCMC}$ based edible films were typical of cellulose films. The curves showed a relatively small slope at a low water activity, with an exponential increase at high water activity (above 0.7 ) solely due to the higher sorption of water molecules by NaCMC and HPC.

Water sorption isotherms were fitted into four different models. These are BET [8], GAB [9], Smith [8] and Halsey [8] models which are represented in Eqs (1) to (4).

$$
\begin{gathered}
1 /\left[\left(1-a_{\mathrm{w}}\right) M\right]=1 / M_{\mathrm{m}}+\left[1 /\left(C M_{\mathrm{m}}\right]\left[\left(1-a_{\mathrm{w}}\right) / a_{\mathrm{w}}\right]\right. \\
M=\frac{m_{0} C k a_{\mathrm{w}}}{\left(1-k a_{\mathrm{w}}\right)\left(1-k a_{\mathrm{w}}+C k a_{\mathrm{w}}\right)} \\
M=M_{\mathrm{b}}-M_{\mathrm{a}} X\left[\ln \left(1-a_{\mathrm{w}}\right)\right] \\
\ln M=a+b X\left\{\ln \left[-\ln \left(a_{\mathrm{w}}\right)\right]\right\}
\end{gathered}
$$

As a result of the calculations GAB model were chosen as the most suitable model for sorption isotherms of $\mathrm{NaCMC}$ and HPC films.

\section{Water vapour diffusion in films}

Figures 5 and 6 show the mass uptake $\left(M_{\mathrm{t}} / M_{\infty}\right) v s . t^{1 / 2}$ graphs of NaCMC and HPC based films, respectively at different relative humidity levels. The first uptake curve in the microbalance was obtained at $\mathrm{RH}$ of $40 \%$. Large water sorption into the NaCMC film at $40 \% \mathrm{RH}$ level caused a S-shaped uptake curve as shown in Fig. 5. When relative humidity in the column was increased from 60 to $80 \%$, the rate of sorption into the $\mathrm{NaCMC}$ films decreased significantly due to increased mass transfer resistance in the swollen film. Figure 6 indicates that mass uptake curves of HPC film are all concave with respect to $t^{1 / 2}$ axis even at $40 \%$ relative humidity level due to lower water sorption levels in this film. The initial parts of all uptake curves shown in Figs 5 and 6 are linear.

The effective diffusivities of water vapour, $D$, through the films with an initial thickness of $h$ have been determined from the slope of the linear region of the $M_{\mathrm{t}} / M_{\infty} v s . t^{1 / 2}$ curve by using Eq. (5) [10].

$$
M_{\mathrm{t}} / M_{\infty}=\left(16 D / h^{2} \pi\right)^{1 / 2} t^{1 / 2}
$$

where $h$ is film thickness and $M_{\mathrm{t}}$ and $M_{\infty}$ are amounts of water vapour adsorbed at time $t$ and at equilibrium, respectively. 


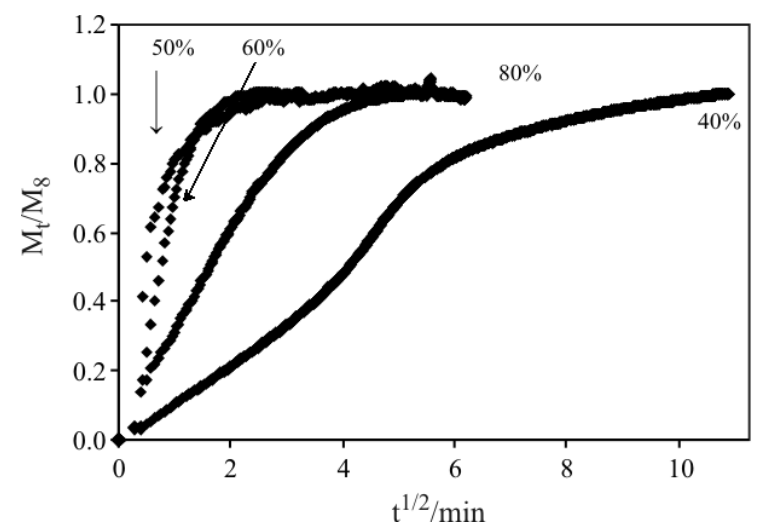

Fig. 5 Mass uptake curves of $\mathrm{NaCMC}$ film at different relative humidity values in microbalance. The films were prepared with $3 \% \mathrm{NaCMC}$ in the solution

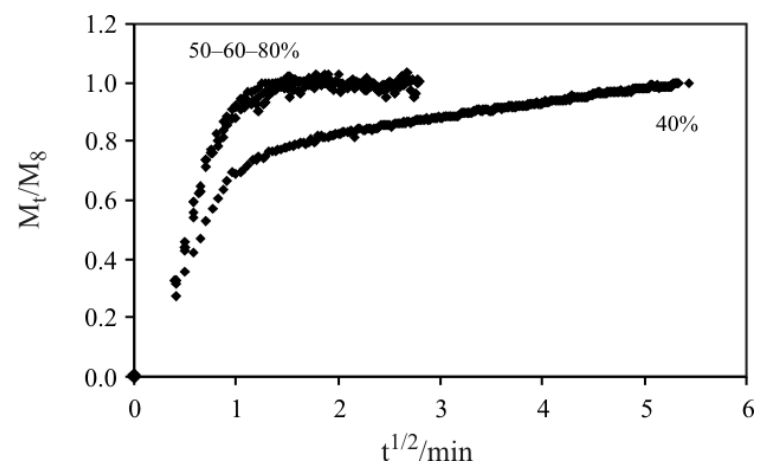

Fig. 6 Mass uptake curves of HPC at different relative humidity values in microbalance. The films were prepared with $3 \%$ HPC in the solution

Table 1 Diffusion coefficient of water vapor in edible films at different relative humidities at $25^{\circ} \mathrm{C}$

\begin{tabular}{ccc}
\hline $\mathrm{RH} / \%$ & \multicolumn{2}{c}{$\mathrm{D} \cdot 10^{14} / \mathrm{m}^{2} \mathrm{~s}^{-1}$} \\
\hline & $\mathrm{NaCMC}$ & $\mathrm{HPC}$ \\
\hline 40 & 7 & 165 \\
50 & 275 & 283 \\
60 & 818 & 241 \\
80 & 88 & 235 \\
\hline
\end{tabular}

The calculated diffusion coefficients of water vapour in $\mathrm{NaCMC}$ and $\mathrm{HPC}$ based films prepared from 3 mass \% polymer solution are listed in Table 1.

HPC based edible films have higher diffusion coefficient values than $\mathrm{NaCMC}$ based films. This is due to the presence of crystalline phase in $\mathrm{NaCMC}$ films, which act as a barrier for diffusion of water vapour. The diffusion coefficient of water vapour in $\mathrm{NaCMC}$ film decreased significantly when relative humidity was increased from 60 to $80 \%$. This may be due to clustering of water in the film structure or gel formation, which could also hinder water vapour diffusion. It should also be noted that Eq. (5) gives approximate values for the diffusivities in
NaCMC films corresponding to 40 and $80 \%$ relative humidities due to strong swelling of the films.

\section{Conclusions}

In this study, NaCMC and HPC based edible films were prepared and characterized to obtain information about the packaging properties of these films. Scanning electron micrographs have shown that HPC based edible films had higher porosity with more homogenous distribution of the pores than those of $\mathrm{NaCMC}$ based films. Based on X-ray diffraction analysis, it was observed that HPC films have an amorphous structure while $\mathrm{NaCMC}$ films have crystalline order. Differential scanning calorimetry indicated the presence of an endotherm having maximum between $83-98^{\circ} \mathrm{C}$ for $\mathrm{NaCMC}$ films and $70-85^{\circ} \mathrm{C}$ for HPC films due to dehydration and evaporation of water from the films. In addition, glass transition temperatures of both films were found to be below room temperature.

Water sorption capacity of the films was found to be lower from the experiments conducted in the microbalance, which may be due to insufficient drying of the films before the experiments. NaCMC based edible films showed lower diffusion coefficient values than HPC based films especially at low relative humidity levels due to the presence of crystalline phase in these films. Based on these results it can be concluded that HPC based films show better barrier property for decreasing the respiration rate from food.

\section{References}

1 H. J. Park, C. L. Weller, P. J. Vergano and R. F. Testin, J. Food Sci., 58 (1993) 1361.

2 J. N. Coupland, N. B. Shaw, F. J. Monahan, E. D. O'Riordan and M. O'Sullivan, J. Food Eng., 43 (2000) 25.

3 K. N. Turhan and F. Şahbaz, J. Food Eng., 61 (2003) 459.

4 G. G. Buonocore, M. A. Del Nobile, C. Di Martino, G. Gambacorta, E. La Notte and L. Nicolais, J. Food Eng., 60 (2003) 99.

5 E. Ayranci, B. S. Büyüktaş and E. E. Cetin, Lebensm. Wiss. Technol., 30 (1997) 101.

6 E. Princi, S. Vicini, E. Pedemonte, V. Arrighi and I. McEwen, J. Therm. Anal. Cal., 80 (2005) 369.

7 E. Robens, K. Rübner and P. Staszczuk, J. Therm. Anal. Cal., 76 (2004) 639.

8 R. Baldev, A. Eugene, K. R. Kumar and Siddarramaiah, J. Appl. Polym. Sci., 84 (2001) 1193.

9 A. D. Roman-Gutierrez, S. Guilbert and B. Cuq, J. Cereal Sci., 36 (2002) 347.

10 J. Crank, Oxford University Press, Oxford 1976. 